\title{
Evaluation and Detection of Geothermal Potential Zones in Yankari Park, South- Central Part of Bauchi State, North-Eastern Nigeria
}

\author{
${ }^{* 1,3}$ ABUBAKAR, AJ; ${ }^{1}$ HASHIM, M; ${ }^{1,2}$ POUR, AB \\ ${ }^{l}$ Geoscience and Digital Earth Centre (INSTeG), Research Institute for Sustainable Environment (RISE), Universiti Teknologi Malaysia \\ (UTM) \\ ${ }^{2}$ Korea Polar Research Institute (KOPRI), Songdomirae-ro, Yeonsu-gu, Incheon 21990, Republic of Korea \\ ${ }^{3}$ Department of Geography, Faculty of Science, Kaduna State University, P. M. B. 2339, Kaduna, Nigeria \\ "Corresponding Author E-mail: abusuhayl77@gmail.com
}

\begin{abstract}
Exploiting geothermal (GT) resources requires first and foremost locating suitable areas for its development. The focus of this paper is to explore the applicability of mapping GT related anomalies by identifying mineralogy and lithological features at regional scale using image enhancement techniques on Landsat 8 satellite data. A combination of established Band ratios from literature were implemented on Landsat 8 optical bands using innovative digital image processing and knowledge-based spectral information extraction techniques which enhanced surface mineralogy and possible alteration areas of interest. The results indicate that ratios using bands; $7 / 4,6 / 3,5 / 7$ and $6 / 7$, $4 / 3,5 / 6$ and 7/5, 5/4, 6/7 respectively as RGB, were unique but corroborative in enhancing and identifying; clay rich rocks, iron oxides, micas, carbonates and possible hydrothermal alteration zones related to GT anomaly. The results could have implication for GT exploration in especially unexplored regions where expensive airborne surveys are unaffordable.
\end{abstract}

\section{DOI: https://dx.doi.org/10.4314/jasem.v22i9.03}

Copyright: Copyright $(92018$ Abubakar et al. This is an open access article distributed under the Creative Commons Attribution License (CCL), which permits unrestricted use, distribution, and reproduction in any medium, provided the original work is properly cited.

Dates: Received: 01 July 2018; Revised: 22 August: 2018; Accepted: 12 September 2018

Keywords: Band ratios, Landsat 8 (OLI), Geothermal, Minerals

Globally, there is a serious energy concern as a result of the combustion of fossil fuels which causes climate change. The exhaustibility of fossil fuels, their unreliability and environmental implications have resulted in the search for alternative sources of energy. Geothermal (GT) energy, which is the energy of the 'Earths Heat', offers a renewable and reliable source of energy. However, as with most renewable energies, it is inherently regional and site specific, mostly associated with areas of magmatic episodes and crustal plate movements. Exploiting geothermal resources requires an initial identification of suitable areas for harnessing it. Remote sensing data can be used to detect indicator minerals as surrogates for assessing potential GT sites. The techniques involved in GT exploration using remote sensing, despite being complementary to in-depth geological surveys, has nevertheless establishes itself as an invaluable step in the prefeasibility stages of GT exploration due to its synoptic capability of covering large areas cost effectively, by narrowing targets prior to a substantial survey. Detailed mineralogical studies of GT fields have been done by previous studies, which revealed an array of alteration minerals related to GT settings (Calvin et al., 2015; Littlefield and Calvin, 2014; Vaughan et al., 2003). The class of common alteration minerals associated with GT systems which are detectable in remote sensing are limited. Many minerals have diagnostic spectral properties and features such as; band center, strength, shape and width which are used to identify species with high confidence (Pour and Hashim, 2015b). Laboratory and remote sensing spectral data are usually separated into wavelength ranges on the basis of their absorption features and the atmospheric windows through which the earth surface is measured (Calvin et al., 2015). In the visible, near infrared, and short-wave infrared (VNIR/SWIR) (0.4to 2.5 m), moderate and lowtemperature surfaces are sensed because of the sunlight they reflect (Pour and Hashim, 2011a). Absorption features occur as a result of electronic orbital configuration of transition metals (generally iron or copper) in various crystallographic sites and from the combination and overtones of molecular vibrations from species such as hydroxyl, water, carbonate, and sulfate. This region of the electromagnetic spectrum is most sensitive to iron oxides, oxy-hydroxides, and ligands resulting from high or low temperature alteration (Clark, 1999). The ability to readily discriminate minerals by their unique spectral characteristics has been, in general, the basis for the use of the techniques in economic mineral exploration (Pour and Hashim, 2011b), and in 
particular, the basis in geothermal exploration using associated minerals as proxy (Calvin et al., 2015).

The objective of this study is to enhance and identify geothermal potential zones using hydrothermal alteration mineral indicators by applying Band ratioing as image transformation technique to VNIRSWIR bands of Landsat 8 at regional scale.

\section{MATERIALS AND METHODS}

Study Area, Geology and Geothermal Implications: The Yankari Park is located in the south-central part of Bauchi State, in northeastern Nigeria. It covers an area of about 2,244 square kilometers (866 sq. mi) (Olokesusi, 1990) and is chosen for the study because the Park is not within the urban fringe thus satellite image data from the area may not be affected by the effect of urban heat island (UHI) characterized by built up areas in the city which could affect or distort the results of subtle geothermal anomalies. Spectral reflectance characteristic of specific earth features will also be more highlighted for detection. Satellite sensors which produce images are capable of detecting "Blind geothermal sources" not easily detectable using conventional survey methods (Heasler et al., 2009; Abubakar et al., 2017a). Thermal springs in the Park include; Dimmil, Gwana and Mawulgo. The famous Wikki thermal spring which has a temperature of about 32 degrees Celsius have been used as a tourist attraction in the Park. The presence of the thermal springs which are hydrothermal systems, within the Park motivates the study. Geologically, Yankari Park lies on the Kerri formation, of Tertiary age, which is composed of sandstone, silt stones, kaolinites and grits. Underneath this lies the Gombe formation, of Cretaceous age, composed of sandstones, silt stones, and ironstones. The valleys of the Gaji, Yashi and Yuli Rivers are filled with Alluvium of more recent age. Sandy loams and clayey soils of riverine alluvium occur in the valley of the Gaji, Yashi and Yuli Rivers. East of the Gaji valley is a 5-7 km wide band of very poor sandy soils that support a shrub savanna formation (Abubakar et al., 2006). Nigeria, being in a tectonically stable region rarely experiences crustal instability, except for the occasional minor earth tremor in the southwestern part of the country (Osagie, 2008). The Nigerian land mass has always been regarded as an aseismic intra-plate, however, historical data indicated that minor crustal disturbances have occurred in the last 50 years in different locations in the country (Ajakaiye et al., 1988). There is however, many extinct volcanic features in the Jos plateau and the north eastern and western part of the country. Surface expressions such as warm springs have been identified including; Ikogosi, Ruwan Zafi, Akiri, and Wikki are some of the obvious manifestations (Abubakar et al., 2017b). In 2011, a fumarole activity occurred where gaseous emissions were observed in Ndanijan Kargo hill at Abaduguri range in Funakaye local government of Gombe state northeast of the Yankari Park. This occurred for 7 months, experts from Nigeria's Center for Geodesy and Geodynamics have tested the gaseous emissions, which had an odour of burning plastic, and revealed that the emission had magmatic origins and may be related to dormant volcanic system of the Pindiga formation (Abdullahi et al., 2014). There may be several undocumented or unexplored geothermal manifestations around the country which could serve as sources for renewable energy use or other GT exploitation requiring less heat from the ground (Abubakar et al., 2017b). Recent technological advances in satellite remote sensing could aid a comprehensive and cost effective exploration and mapping of potential areas in the country which could lead to geothermal resource exploitation and development. A simplified geology map in figure 1 illustrates Nigeria's geological areas with Yankari Park location (Study area) in box.

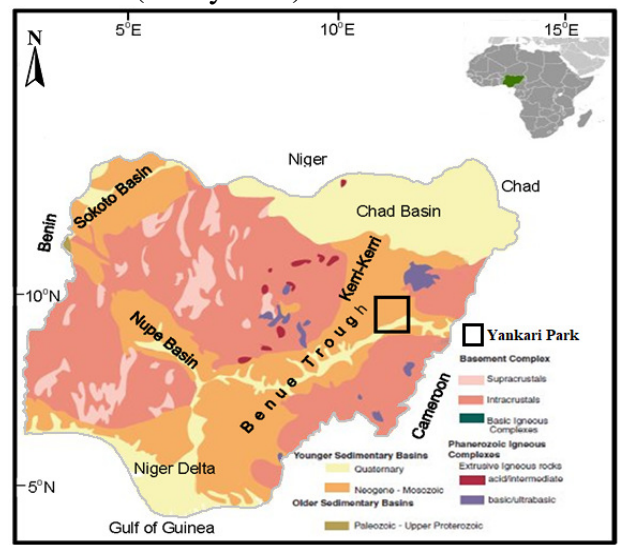

Fig 1. Simplified Geological Map of Nigeria showing Yankari Park (Abubakar et al., 2017b)

Remote sensing data: In this study, the Landsat 8 imagery is used. The Landsat- 8 was launched on the $4^{\text {th }}$ of February, 2013 from the Vandenberg Air force Base in California as part of the Landsat Data Continuity Mission (LDCM) which has been in operation since 1972 resulting in a generation of earth orbiting satellites including Landsat 1, 2, 3 and 4, 5 and 7. The satellite is a successor to its immediate predecessor; Landsat 7. The Landsat 8 is an American Earth Observation Satellite operated by NASA. It is characterized by two sensors; the Operational Land Imager (OLI) and the Thermal Infrared Sensor (TIRS) (Storey et al., 2014). The OLI collects image data in nine (9) channels or bands ranging from the VNIR to SWIR portions of Electromagnetic Spectrum (EMS). The Landsat 8's objective is to provide timely, high quality visible and infrared images of all landmass and 
near coastal areas of the earth. It has a design life time of five years and carries 10 years of fuel consumables. Designed for a $705 \mathrm{~km}$ sun- synchronous orbit, Landsat 8 offers a 16-day repetitive Earth coverage, completely orbiting the earth every 98.9 minutes. It builds and periodically refresh a global archive of sunlit, substantially cloud free land images. The Landsat 8 system is robust, providing high resolution multispectral data, high volume of data by routinely collecting 650 scenes per day as opposed to 400 scenes in previous Landsat missions (Storey et al., 2014). The OLI sensor collects image data for nine shortwave spectral bands over a $190 \mathrm{~km}$ swath with a $30 \mathrm{~m}$ spatial resolution for all bands except the $15 \mathrm{~m}$ panchromatic band. The widths of several OLI bands are refined to avoid atmospheric absorption features within ETM+ bands. The biggest change occurs in OLI band 5 $(0.845-0.885 \mu \mathrm{m})$ to exclude a water vapor absorption feature at $0.825 \mu \mathrm{m}$ in the middle of the ETM+ near infrared band (band 4; 0.775-0.900 $\mu \mathrm{m}$ ) (Markham et al., 2014). The OLI panchromatic band, band 8 , is also narrower relative to the ETM+ panchromatic band to create greater contrast between vegetated areas and land without vegetation cover (Storey et al., 2014)

Data processing: Atmospheric correction: The Landsat 8 image data was first layer stacked using the Environment for Visualizing Imagery (ENVI 5.1) software and then atmospherically corrected using the Internal Average Relative Reflection - IARR method in ENVI. The method is suitable where the study area is sparsely vegetated (Pour and Hashim, 2015a), in this case a Sudan savanna region. The IARR algorithm is also preferred in mineralogical mapping especially as it does not necessitate a prior knowledge of samples to be collected from the field (Pour and Hashim, 2015a). The data is thus converted into relative reflectance to facilitate subsequent spectral information extraction.

Band ratio transformation: Band ratioing is a multispectral image processing method that involves the division of one spectral band by another.

This division results in the ratio of spectral reflectance measured in the one spectral band to the spectral reflectance measured in another spectral band. Identical surface materials can give different brightness values because of the topographic, slope and aspect, shadows, or seasonal changes in sunlight illumination angle and intensity.

These variations can influence the viewer's interpretations leading to misguided results. Band ratioing transforms the data thereby minimizing the effects of such environmental conditions (Jensen and
Lulla, 1987). In addition to reducing the effects of environmental factors, band ratios may also provide unique information not available in any single band that is useful for discriminating between soils and vegetation (Jensen and Lulla, 1987).

Dividing one ratio by the other produces images that shows relative intensities. There are many sensitive bands for ratios and in this study we employed the (Sabins, 1997, Abrams, 1983 and Kaufmann, 1988) band ratios from literature.

The band equivalents from previous Landsat bands were substituted to correspond to their equivalents in Landsat 8 in terms of VNIR and SWIR portions of the EMS. This ensures the accomplishing of similar results despite the variation in band designation. The Band ratios were executed using standard routine ENVI transformation and processing tools.

\section{RESULTS AND DISCUSSION}

The Sabins (1997) band ratio as in (Sabins, 1999) used Landsat TM bands combinations using bands 7, 3, 5, 2 and 4. This correspond to bands 7, 4, 6, 3 and 5 in Landsat 8 . Thus, the band ratio $7 / 3,5 / 2,4 / 7$ is equivalent to band ratio $7 / 4,6 / 3,5 / 7$ in RGB. The resulting image as shown in figure 2 , indicates yellow as hydrothermal alteration areas, black identifies water, the green indicates vegetation (dark green) and clay rich rocks (light green), blue shows sand, red, pink or magenta indicates some mineral rocks-iron oxides (Sabins, 1999)

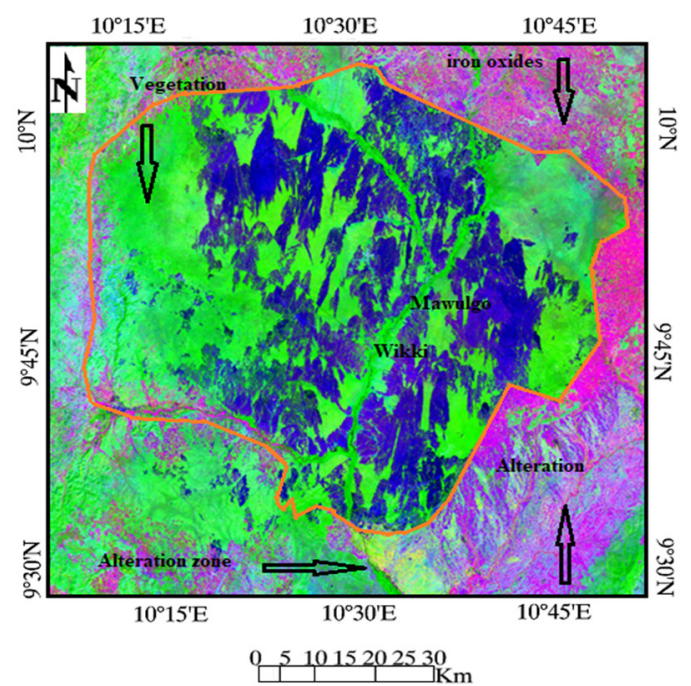

Fig 2: Landsat 8 band ratio 7/4, 6/3, 5/7 image for Yankari scene and environs.

Band ratios 5/7, 3/2 and 4/5 of Landsat TM used in (Abrams et al., 1983) are selected for the red, green 
and blue (RGB) channels equivalents $6 / 7,4 / 3$ and 5/6 on Landsat 8 which correspond to wavelength regions $1.65 / 2.2 \mu \mathrm{m}, 0.66 / 0.56 \mu \mathrm{m}$ and $0.83 / 1.65 \mu \mathrm{m}$ in the EMS. The results of the band combinations indicates Iron oxide-rich areas displayed as green due to the presence of ferric iron charge transfer band in the ultraviolet, and clay-rich areas are displayed as red, due to presence of hydrous minerals absorption band near $2.2 \mu \mathrm{m}$. Yellow or orange areas represent the areas where both clay and iron oxide minerals are present (Abrams et al., 1983; Abubakar et al., 2017c). The result is shown on figure 3 .

The (Kaufmann, 1988) ratio combinations using bands 7, 4, 3 and 5 in Landsat TM, is equivalent to bands 7, 5,4 and 6 in Landsat 8. The ratio 7/4, 4/3 and 5/7 thus corresponds to ratio $7 / 5,5 / 4$ and $6 / 7$ using Landsat 8 bands. The result indicates band 5/4 displays vegetation in bright tones caused by high reflectance of mesostructure in NIR band in contrast to the steep fall-off of reflectance towards the visible (Landsat 8 band 4 or band 3 in Landsat TM) due to intense chlorophyll absorption (Kaufmann, 1988).

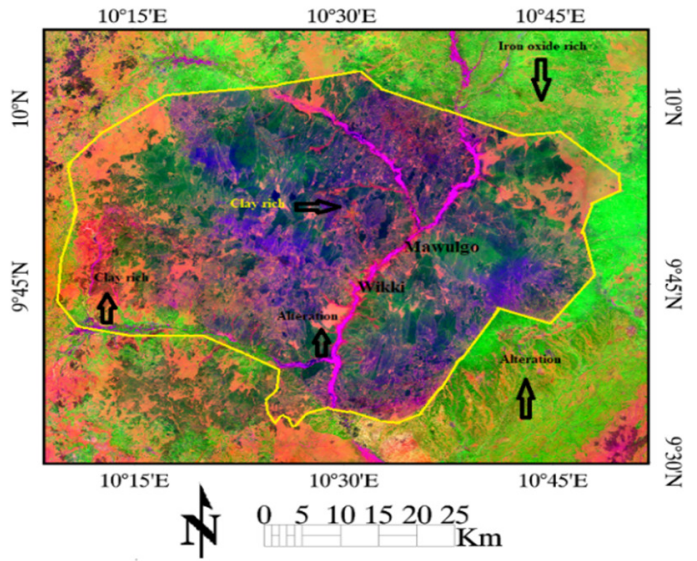

Fig 3: Landsat 8 band ratio 6/7, 4/3, 5/6 image for Yankari scene and environs

Clay minerals containing water (bound or unbound) micas, carbonates and hydrates are enhanced by band ratio $6 / 7$ (5/7 in TM). The ferric and ferrous iron is best enhanced by band ratio 7/5 (7/4 in TM) due to major electronic transition bands in NIR (at $\sim 0.87 \mathrm{um}$ ) and the visible charge transfer bands in ultra violet and unaffected SWIR range (Kaufmann, 1988). The composite color image created by band ratio $7 / 5,5 / 4$, $6 / 7$ (7/4, 4/3, 5/7 in TM) displayed as RGB, results in an image which shows red color represents minerals containing iron ions, green represent vegetated zones and blue represent $\mathrm{OH} / \mathrm{H} 2 \mathrm{O}-$, SO4- or CO-bearing minerals (Kaufmann, 1988). This is illustrated in figure 4 .

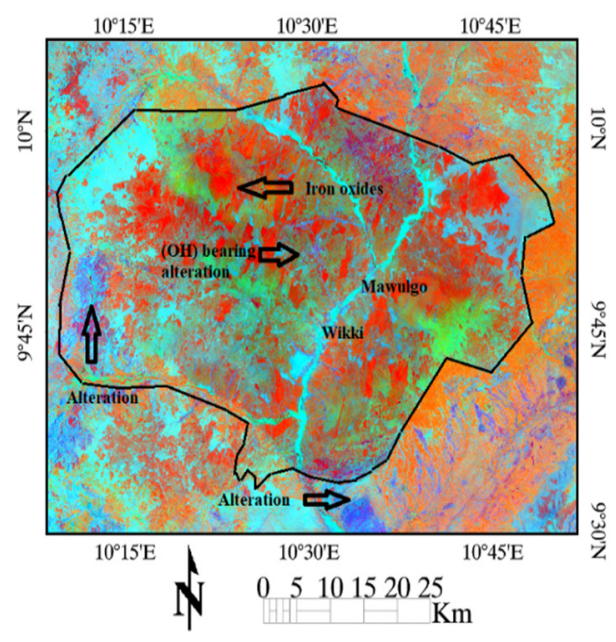

Fig 4: Landsat 8 band ratio 7/5, 5/4, 6/7 image for Yankari scene and environs

Conclusions: As observed from the results of the investigation, the Landsat 8 VNIR-SWIR data successfully highlighted lithology, vegetation and important mineralogy such as clay-rich zones, ironoxides, mica, sulfates and carbonates. Although no hot springs are identified directly, identification of altered mineral zones especially; clays, sulfates and carbonates which are related to hydrothermal alteration, could serve as proxy for locating fossil geothermal systems. This has implication for GT exploration in unexplored savanna regions where expensive airborne surveys are unaffordable and thus serve as a useful tool for prefeasibility stage narrowing of targets to aid subsequent detailed investigations.

Acknowledgement: The authors kindly acknowledge the Universiti Teknologi Malaysia, the Kaduna State University and Korea Polar Research Institute for supporting this investigation. The Earth Resources Observation System (EROS) Data Centre of the U.S.G.S. from which the image data used for study were obtained is hereby also acknowledged.

\section{REFERENCES}

Abdullahi, B. U., Rai, J. K., Olaitan, O., Musa, Y. (2014). A Review of the Correlation Betweeen Geology and Geothermal Energy in Northeastern Nigeria. Journal of Applied Geology and Geophysics (IOSR$J A G G), 2(3), 74-83$.

Abrams, M. J., Brown, D., Lepley, L. and Sadowski, R. (1983). Remote Sensing for Porphyry Copper Deposits in Southern Arizona. Economic Geology, 78(4), 591-604.

Abubakar, A., Hashim, M., Pour, A. (Year) Published. Spectral Mineral Mapping for Characterization of Subtle Geothermal Prospects Using Aster Data. 
Journal of Physics: Conference Series, 2017a. IOP Publishing, 012024.

Abubakar, A. J. A., Hashim, M., Pour, A. B. (2006). Hydrothermal Alteration Mapping of Mineralogical Imprints Associated with Subtle Geothermal System Using Mixture Tuned Matched Filtering Approach on Aster Vnir and Swir Data.

Abubakar, A. J. A., Hashim, M., Pour, A. B. (2017b). Hydrothemal Alteration Mapping Using FeatureOriented Principal Component Selection (Fpcs) Method to Aster Data: Wikki and Mawulgo Thermal Springs, Yankari Park, Nigeria. ISPRS-International Archives of the Photogrammetry, Remote Sensing and Spatial Information Sciences, 1-5.

Abubakar, A. J. A., Hashim, M., Pour, A. B. (2017c). Identification of Hydrothermal Alteration Minerals Associated with Geothermal System Using Aster and Hyperion Satellite Data: A Case Study from Yankari Park, Ne Nigeria. Geocarto International, (just-accepted), 1-57.

Ajakaiye, D., Olatinwo, M., Scheidegger, A. (1988). Another Possible Earthquake near Gombe in Nigeria on the 18-19 June 1985. Bulletin of the Seismological Society of America, 78(2), 10061010.

Calvin, W. M., Littlefield, E. F., Kratt, C. (2015). Remote Sensing of Geothermal-Related Minerals for Resource Exploration in Nevada. Geothermics, 53, 517-526.

Clark, R. N. (1999). Spectroscopy of Rocks and Minerals, and Principles of Spectroscopy. Manual of remote sensing, 3, 3-58.

Heasler, H. P., Jaworowski, C., Foley, D. (2009). Geothermal Systems and Monitoring Hydrothermal Features. Geological Monitoring, 105-140.

Jensen, J., Lulla, K. (1987). In Prentice Hall. Introductory digital image processing: A remote sensing perspective.

Kaufmann, H. (1988). Concepts, Processing and Results. International Journal of Remote Sensing, 9(10-11), 1639-1658.

Littlefield, E. F., Calvin, W. M. (2014). Geothermal Exploration Using Imaging Spectrometer Data over
Fish Lake Valley, Nevada. Remote Sensing of Environment, 140, 509-518.

Markham, B., Barsi, J., Kvaran, G., Ong, L., Kaita, E., Biggar, S., Czapla-Myers, J., Mishra, N., Helder, D. (2014). Landsat-8 Operational Land Imager Radiometric Calibration and Stability. Remote Sensing, 6(12), 12275-12308.

Olokesusi, F. (1990). Assessment of the Yankari Game Reserve, Nigeria: Problems and Prospects. Tourism Management, 11(2), 153-163.

Osagie, E. O. (2008). Seismic Activity in Nigeria. The Pac Jour Sci and Tech, 9(2), 1-6.

Pour, A., Beiranv, Hashim, M. (2011a). Application of Advanced Spaceborne Thermal Emission and Reflection Radiometer (Aster) Data in Geological Mapping. International Journal of Physical Sciences, 6(33), 7657-7668.

Pour, A., Beiranv, Hashim, M. (2011b). The Earth Observing-1 (Eo-1) Satellite Data for Geological Mapping, Southeastern Segment of the Central Iranian Volcanic Belt, Iran. International Journal of Physical Sciences, 6(33), 7638-7650.

Pour, A. B., Hashim, M. (2015a). Hydrothermal Alteration Mapping from Landsat-8 Data, Sar Cheshmeh Copper Mining District, South-Eastern Islamic Republic of Iran. Journal of Taibah University for Science, 9(2), 155-166.

Pour, A. B., Hashim, M. (2015b). Structural Mapping Using Palsar Data in the Central Gold Belt, Peninsular Malaysia. Ore Geology Reviews, 64, 1322.

Sabins, F. F. (1999). Remote Sensing for Mineral Exploration. Ore Geology Reviews, 14(3), 157-183.

Storey, J., Choate, M., Lee, K. (2014). Landsat 8 Operational Land Imager on-Orbit Geometric Calibration and Performance. Remote Sensing, 6(11), 11127-11152.

Vaughan, R. G., Calvin, W. M., Taranik, J. V. (2003). Sebass Hyperspectral Thermal Infrared Data: Surface Emissivity Measurement and Mineral Mapping. Remote Sensing of Environment, 85(1), 48-63. 